\title{
Pengaruh kecerdasan emosional terhadap hasil belajar matematika siswa kelas VII MTs. NW Pagutan
}

\author{
Mauliddin ${ }^{1 *}$, Siti Patimah2* \\ * Affiliasi: Universitas Islam Negeri Mataram
}

\section{Keywords: Emotional Intelligence, Mathematics, Learning outcomes}

Kata Kunci: Kecerdasan emosional, Hasil belajar, Matematika
A b s t $\mathbf{r}$ a $\mathbf{c}$ t: The purpose of this study was to determine the influence of emotional intelligence on the mathematics learning outcomes of MTs students. NW Pagutan. This type of research is ex-post facto with a quantitative approach. The subjects of this study were seventh grade students at MTs. NW Pagutan. The data collection method used in this research is in the form of questionnaires and documentation. The results obtained in this study are the magnitude of $\mathrm{F}$ count is 29,020. Meanwhile, the value of $F_{\text {tabel }}$ is at a significance level of $5 \%$ with $\mathrm{N}=19$, which is 4.45 . Then $F_{\text {hitung }} \geq F_{\text {tabel }}$ with a significance/probability level of $0.000<0.05$, meaning that it is significant, so H_a is accepted and H_o is rejected. The conclusion that can be drawn from this research is that there is an influence of emotional intelligence on the mathematics learning outcomes of seventh grade students of MTs NW Pagutan. The suggestions put forward in this study are that teachers are expected to be more familiar with the emotional conditions of students, so that teachers can choose appropriate learning methods or models so that they can help students achieve maximum learning outcomes.

A b s t r a k: Tujuan penelitian ini adalah untuk mengetahui adanya pengaruh kecerdasan emosional terhadap hasil belajar Matematika siswa MTs. NW Pagutan. Jenis penelitian ini adalah ex-post facto dengan pendekatan kuantitatif. Subjek dari penelitian ini adalah siswa kelas VII di MTs. NW Pagutan. Metode pengumpulan data yang digunakan dalam penelitian ini berupa angket dan dokumentasi. Hasil yang diperoleh dalam penelitian ini yaitu besarnya $F_{\text {hitung }}$ adalah 29,020. Sementara nilai $F_{\text {tabel }}$ pada taraf signifikansi 5\% dengan $\mathrm{N}=19$, yaitu sebesar 4,45. Maka $F_{\text {hitung }} \geq F_{\text {tabel }}$ dengan tingkat signifikansi/ probabilitas $0,000<0,05$, artinya signifikan, sehingga $H_{a}$ diterima dan $H_{o}$ ditolak. Kesimpulan yang dapat diambil dari penelitian ini yaitu terdapat pengaruh kecerdasan emosional terhadap hasil belajar matematika siswa kelas VII MTs. NW Pagutan. Adapun saran yang diajukan dalam penelitian ini yaitu guru diharapkan untuk lebih mengenal kondisi emosional yang dimiliki siswa, sehingga guru dapat memilih metode ataupun model pembelajaran yang sesuai sehingga dapat membantu siswa mencapai hasil belajar yang maksimal.

\footnotetext{
${ }^{1}$ Coresponden to author: Program Studi Tadris Matematika-FTK UIN MATARAM, J16. Gajah Mada Jempong, Indonesia. (83116), E-mail address: mauliddin1893@uinmataram.ac.id

2 E-mail addresses: sifa.1808@gmail.com
} 


\section{Article Info}

Article History: Received 03 Agustus 2021|Revised 20 Agustus 2021|Accepted 08 September 2021 | Available online 20 September 2021

\section{Pendahuluan}

Pendidikan pada dasarnya adalah usaha sadar untuk menumbuh kembangkan potensi sumber daya manusia dengan cara mendorong dan memfasilitasi kegiatan belajar mengajar. Karena dengan adanya pendidikan maka seseorang dapat memiliki kecerdasan, baik kecerdasan intelligensi, emosional maupun spiritual, akhlak mulia serta keterampilan yang bermanfaat bagi diri sendiri dan masyarakat. Kecerdasan emosional (EQ) merupakan kemampuan mengenali perasaan diri sendiri dan perasaan orang lain, memotivasi diri sendiri, dan mengolah emosi diri dengan baik pada diri sendiri serta hubungannya dengan orang lain. Kecerdasan emosi perlu diasah sejak dini karena kecerdasan emosi merupakan salah satu poros keberhasilan individu dalam berbagai aspek kehidupan. Sesuai dengan pendapat Goleman yang dikutip oleh Patton, bahwa para ahli psikologi sepakat kalau kecerdasan intelligensi (IQ) hanya mendukung sekitar 20 persen faktor yang menentukan keberhasilan, sedangkan 80 persen sisanya berasal dari faktor lain termasuk kecerdasan emosinal.

Kemampuan anak mengembangkan kecerdasan emosinya, berkorelasi positif dengan keberhasilan akademis, sosial, dan kesehatan mentalnya. Anak yang memiliki kecerdasan emosi tinggi identik dengan anak yang bahagia, bermotivasi tinggi, dan mampu bertahan dalam menjalani berbagai kondisi stres yang dihadapi. Kecerdasan emosional perlu ditumbuh kembangkan kepada siswa, agar siswa dapat mengelola kehidupan emosionalnya lebih terkendali dan terarah. Kecerdasan emosional merupakan bagian mental yang sering terabaikan dalam proses belajar mengajar. Dalam pergaulan sehari-hari emosi yang stabil sangat dibutuhkan. Namun tidak semua siswa dapat mengatur emosinya sendiri dengan cerdas. Saat seorang siswa tidak mampu mengelola emosinya dengan cerdas akan mempengaruhi cara berfikir dalam hal menilai dirinya. Sehingga hal tersebut dapat menyebabkan timbulnya pandangan negatif tentang dirinya dan mempengaruhi hasil belajar siswa.

Sudjana mengatakan bahwa hasil belajar adalah suatu akibat dari proses belajar dengan menggunakan alat pengukuran yaitu berupa tes yang disusun secara terencana baik tes tulis maupun tes lisan maupun tes perbuatan. Hasil belajar siswa dapat dilihat dari berbagai pembelajaran, salah satunya pembelajaran matematika. Matematika merupakan mata pelajaran yang selalu ada dalam setiap jenjang pendidikan, hanya saja yang membedakan pada setiap jenjangnya adalah pendalaman materi yang terus lebih meningkat. Hasil belajar matematika adalah suatu perubahan perilaku baru yang merupakan hasil pemberian pengalaman yang diterima siswa pada proses pembelajaran yang mencakup aspek kognitif, afektif, dan psikomotor yang dapat diukur keberhasilannya melalui tes tulis maupun lisan.

Berdasarkan penelitian yang dilakukan oleh Nurul Febriana, tentang pengaruh kecerdasan emosional terhadap hasil belajar pada mata pelajaran ekonomi, dari hasil penelitian tersebut dinyatakan bahwa terdapat pengaruh kecerdasan emosional terhadap hasil belajar siswa 
pada mata pelajaran ekonomi, maka secara tidak langsung kecerdasan emosional tersebut mempengaruhi hasil belajar siswa.

Melihat fakta di lapangan, khususnya di MTs. NW Pagutan menunjukkan bahwa terdapat beberapa peserta didik yang dapat mengontrol emosinya dengan baik, cenderung mampu bersikap baik dan tenang saat proses pembelajaran maupun saat mengerjakan soal-soal tes. Sedangkan peserta didik yang sulit mengontrol emosi cenderung bersikap menyimpang saat proses pembelajaran dan mudah menyerah saat mengerjakan soal-soal tes. Hal ini dikarenakan peserta didik merasa lelah, jenuh, tertekan dan terburu-buru. Kebanyakan dari mereka juga kurang rasa percaya diri untuk belajar matematika, tidak suka belajar matematika dengan alasan bahwa belajar matematika itu susah dipahami dan banyak mengalami kendala dalam menyelesaikan soal matematika.

Keadaan emosi peserta didik juga mempengaruhi mereka pada saat menerima pelajaran. Jika mereka dalam keadaan bosan atau dalam keadaan marah pada seseorang, mereka akan sulit menerima dan memahami pelajaran yang disampaikan oleh pendidik. Oleh karena itu faktorfaktor tersebut menjadi penyebab rendahnya hasil belajar peserta didik. Senada dengan bapak Kadri Ramdhani guru matematika kelas VII MTs. NW Pagutan menyatakan bahwa banyak peserta didik yang tidak memiliki keterampilan emosi, dimana keterampilan emosi yang dimaksud yaitu peserta didik tidak mampu mengendalikan diri seperti bersifat acuh tak acuh, malas dan semangat belajar matematika yang masih rendah. peserta didik juga tidak mampu menjaga suasana hati dan menjaga agar beban stres tidak melumpuhkan kemampuan berpikirnya yang bisa mempengaruhi otak dalam menerima pelajaran, serta peserta didik juga tidak mampu memotivasi diri sendiri seperti contohnya seorang anak mampu menjawab dan menyelesaikan 20 soal dalam suatu latihan, namun kenyataannya anak tersebut hanya mampu menyelesaikan separuh dari soal tersebut, selebihnya tidak dikerjakan dengan alasan merasa lelah, jenuh atau ingin melakukan aktivitas lain.

Hal ini dapat berpengaruh pada hasil belajar karena peserta didik tidak memiliki motivasi untuk belajar. Sehingga banyak peserta didik yang memiliki nilai dibawah KKM (Ketuntasan Keriteria Minimum) khususnya pada pelajaran matematika. Oleh karena itu, sekolah dan pendidik harus bekerja sama untuk membantu mengarahkan para peserta didik yang bermasalah agar mereka bisa meraih hasil belajar yang baik. Untuk mengantisipasi masalah tersebut agar tidak berkelanjutan maka para pendidik harus terus berusaha menggali faktor-faktor yang mempengaruhi rendahnya hasil belajar matematika siswa, salah satunya faktor internal yaitu kecerdasan emosional. Berdasarkan uraian tersebut, melihat pentingnya peranan kecerdasan emosional atau Emotional Quetient (EQ), maka peneliti tertarik dan termotivasi untuk melakukan penelitian yang berjudul "Pengaruh Kecerdasan Emosional Terhadap Hasil Belajar Matematika Siswa Kelas VII MTs. NW Pagutan”.

\section{Metode}

Jenis penelitian yang diginakan dalam penelitian ini adalah penelitian Ex-post facto. Menurut Gay penelitian Ex-post facto adalah penelitian dimana peneliti berusaha menentukan penyebab atau alas an, untuk keberadaan perbedaan dalam perilaku atau status dalam kelompok individu. Pada penelitian ini, terdapat satu variabel bebas dan satu variabel terikat.variabel bebas dalam penelitian ini adalah kecerdasan emosional $(\mathrm{X})$, sedangkan variabel terikatnya adalah hasil 
belajar (Y). Adapun teknik pengambilan sampel yang digunakan dalam penelitian ini adalah teknik sampling jenuh.

\section{Hasil dan Pembahasan}

\section{Deskriptif Data Kecerdasan Emosional dan Hasil Belajar}

Penyajian data meliputi pemaparan hasil penelitian berupa pengaruh kecerdasan emosional menjadi variabel bebas $(\mathrm{X})$ dan hasil belajar siswa menjadi variabel terikat $(\mathrm{Y})$. Jumlah sampel yang diteliti sebanyak 19 siswa. Adapun skor tertinggi angket kecerdasan emosional (X) yaitu 87, skor terendah 51 dan rata-ratanya 69. Sedangkan nilai tertinggi pada hasil belajar siswa (Y) yaitu 85, nilai terendah yakni 55 dan nilai rata-ratanya mencapai 68,47. Untuk lebih jelas data dari kedua variabel tersebut dapat di lihat pada Tabel 1:

Tabel 1. Data Kecerdasan Emosional dan Hasil Belajar 
Case Summaries $^{a}$

\begin{tabular}{|c|c|c|c|}
\hline & & $\begin{array}{c}\text { Kecerdasan } \\
\text { Emosional }\end{array}$ & Hasil Belajar \\
\hline \multicolumn{2}{|l|}{1} & 73 & 60 \\
\hline \multicolumn{2}{|l|}{2} & 81 & 75 \\
\hline \multicolumn{2}{|l|}{3} & 87 & 85 \\
\hline \multicolumn{2}{|l|}{4} & 71 & 65 \\
\hline \multicolumn{2}{|l|}{5} & 84 & 85 \\
\hline \multicolumn{2}{|l|}{6} & 83 & 75 \\
\hline \multicolumn{2}{|l|}{7} & 82 & 80 \\
\hline \multicolumn{2}{|l|}{8} & 72 & 75 \\
\hline \multicolumn{2}{|l|}{9} & 58 & 65 \\
\hline \multicolumn{2}{|l|}{10} & 56 & 60 \\
\hline \multicolumn{2}{|l|}{11} & 62 & 75 \\
\hline \multicolumn{2}{|l|}{12} & 71 & 65 \\
\hline \multicolumn{2}{|l|}{13} & 68 & 75 \\
\hline \multicolumn{2}{|l|}{14} & 56 & 60 \\
\hline \multicolumn{2}{|l|}{15} & 51 & 55 \\
\hline \multicolumn{2}{|l|}{16} & 52 & 56 \\
\hline \multicolumn{2}{|l|}{17} & 62 & 65 \\
\hline \multicolumn{2}{|l|}{18} & 70 & 60 \\
\hline \multicolumn{2}{|l|}{19} & 72 & 65 \\
\hline \multirow[t]{13}{*}{ Total } & $N$ & 19 & 19 \\
\hline & Sum & 1311 & 1301 \\
\hline & Minimum & 51 & 55 \\
\hline & Maximum & 87 & 85 \\
\hline & Mean & 69,00 & 68,47 \\
\hline & Std. Error of Mean & 2,577 & 2,147 \\
\hline & Median & 71,00 & 65,00 \\
\hline & Grouped Median & 70,67 & 67,00 \\
\hline & Range & 36 & 30 \\
\hline & Variance & 126,222 & 87,596 \\
\hline & Kurtosis & $-1,095$ & $-1,000$ \\
\hline & Std. Error of Kurtosis & 1,014 & 1,014 \\
\hline & Std. Deviation & 11,235 & 9,359 \\
\hline
\end{tabular}

a. Limited to first 100 cases.

Dari hasil tabel di atas dapat dilihat nilai kecerdasan emosional dan hasil belajar siswa. Ada yang kecerdasan emosionalnya tinggi namun hasil belajarnya rendah, itu dikarenakan siswa lebih memahami perasaan yang di alaminya, ada juga siswa yang memiliki kecerdasan rendah namun hasil belajarnya tinggi. Ini disebabkan karena masih banyak faktor lain yang mempengaruhi hasil belajar.

\section{Hasil Uji Prasyarat}

Uji Normalitas

Analisis uji normalitas pada masing-masing variabel penelitian dilakukan dengan uji Shapiro-Wilk dapat di lihat pada Tabel 2: 
Tabel 2. Normalitas Shapiro-Wilk

\begin{tabular}{|l|r|r|r|r|r|r|}
\hline \multicolumn{1}{|c|}{ Tests of Normality } \\
\cline { 2 - 8 } & \multicolumn{2}{|c|}{ Kolmogorov-Smirnov $^{\text {a }}$} & \multicolumn{3}{c|}{ Shapiro-Wilk } \\
\cline { 2 - 8 } & Statistic & \multicolumn{1}{c|}{ df } & \multicolumn{1}{c|}{ Sig. } & \multicolumn{1}{c|}{ Statistic } & \multicolumn{1}{c|}{ df } & \multicolumn{1}{c|}{ Sig. } \\
\hline Kecerdasan Emosional &, 120 & 19 &, $200^{\circ}$ &, 943 & 19 &, 302 \\
Hasil Belajar &, 224 & 19 &, 013 &, 912 & 19 &, 081 \\
\hline
\end{tabular}

${ }^{*}$. This is a lower bound of the true significance.

a. Lilliefors Significance Correction

Berdasarkan hasil uji normalitas pada Shapiro-Wilk diketahui bahwa nilai signifikansi Kecerdasan Emosional (X) yaitu sebesar 0,302, dimana nilai signifikansi $>0,05$ maka dapat disimpulkan bahwa populasi data variabel kecerdasan emosional berdistribusi normal. Sedangkan nilai signifikansi dari variabel Hasil Belajar (Y) yaitu 0,081. Dimana nilai signifikansi> 0,05 maka dapat disimpulkan bahwa populasi data variabel hasil belajar juga berdistribusi normal. Jadi, dari hasil tersebut dapat disimpulkan bahwa kedua variabelnya berdistribusi normal.

\section{Uji Linearitas}

Pedoman yang digunakan untuk menentukan kelinearan adalah dengan melihat hasil analisis pada lajur deviation from linearity. Ketentuan yang digunakan untuk pengambilan keputusan adalah jika nilai signifikasi pada lajur deviation from linearity $>0,05$ maka disimpulkan hubungan variabel bebas dengan variabel terikat linear. Sebaliknya jika nilai signifikasi pada lajur deviation from linearity $<0,05$ disimpulkan hubungan variabel bebas dan variabel terikat tidak linear. Hasil pengujian ini dapat di lihat pada Tabel 3:

\section{Tabel 3. ANOVA Table}

\begin{tabular}{|c|c|c|c|c|c|c|c|}
\hline \multicolumn{8}{|c|}{ ANOVA Table } \\
\hline & & & $\begin{array}{l}\text { Sum of } \\
\text { Squares }\end{array}$ & df & Mean Square & $\mathrm{F}$ & Sig. \\
\hline \multirow[t]{5}{*}{ Hasil Belajar * Kecerdasan Emosional } & Between Groups & (Combined) & 1476,737 & 14 & 105,481 & 4,219 & .087 \\
\hline & & Linearity & 994,282 & 1 & 994,282 & 39,771 & ,003 \\
\hline & & Deviation from Linearity & 482,455 & 13 & 37,112 & 1,484 & .378 \\
\hline & Within Groups & & 100,000 & 4 & 25,000 & & \\
\hline & Total & & 1576,737 & 18 & & & \\
\hline
\end{tabular}

Dari hasil uji linieritas diatas dapat dilihat pada ANOVA Table bisa diketahui untuk nilai signifikan pada kolom Sig. sebesar 0,378. Karena signifikan lebih dari 0,05 maka dapat disimpulkan variabel kecerdasan emosional dan hasil belajar siswa terdapat hubungan yang linear. 


\section{Uji Hipotesis}

Analisis Regresi Sederbana

Hasil analisis regresi sederhana ini dapat di lihat pada Tabel 4 :

\section{Tabel 4. Coefficients ${ }^{a}$}

\begin{tabular}{|c|c|c|c|c|c|c|}
\hline \multicolumn{7}{|c|}{ Coefficients $^{a}$} \\
\hline \multirow[b]{2}{*}{ Model } & & \multicolumn{2}{|c|}{ Unstandardized Coefficients } & \multirow{2}{*}{$\begin{array}{c}\begin{array}{c}\text { Standardized } \\
\text { Coefficients }\end{array} \\
\text { Beta }\end{array}$} & \multirow[b]{2}{*}{$t$} & \multirow[b]{2}{*}{ Sig. } \\
\hline & & $B$ & Std. Error & & & \\
\hline 1 & (Constant) & 22,828 & 8,579 & & 2,661 &., 016 \\
\hline & Kecerdasan Emosional & 662 & 123 &, 794 & 5,387 &, 000 \\
\hline
\end{tabular}

a. Dependent Variable: Hasil Belajar

Secara umum rumus persamaan regresi linear sederhana atau persamaan garis regresi adalah $\hat{Y}=a+b X$. Sementara untuk mengetahui nilai koefisien regresi dapat berpedoman pada output table coefficient a $=$ angka konstan dari unstandardized coefficient beta. Dalam hal ini nilainya sebesar 22,828. Angka tersebut merupakan angka konstan yang mempunyai arti bahwa nilai konsisten variabel kecerdasan emosional adalah sebesar 22.828. b = angka koefisien regresi. Nilainya sebesar 0,662. Angka tersebut mengandung arti bahwa setiap penambahan sebesar 1 poin nilai kecerdasan emosional $(\mathrm{X})$, maka nilai hasil belajar $(\mathrm{Y})$ bertambah sebesar 0,662 . Nilai positif pada koefisien regresi menunjukkan arah pengaruh positif. Hal ini menunjukkan bahwa semakin tinggi kecerdasan emosional yang dirasakan oleh individu, maka semakin tinggi pula hasli belajar yang didapatkan, dan begitu juga sebaliknya, semakin rendah kecerdasan emosional yang dirasakan oleh individu, maka semakin rendah tingkat hasil belajar yang didapatkan. Karena nilai koefisien bernilai positif $(+)$, maka dengan demikian dapat dikatakan bahwa kecerdasan emosional $(\mathrm{X})$ berpengaruh positif terhadap hasil belajar $(\mathrm{Y})$. Sehingga persamaan regresinya menjadi $\hat{Y}=22,828+0,662 X$.

\section{Uji Koefisien Determinasi}

Untuk mengetahui besar persentase pengaruh kecerdasan emosional terhadap hasil belajar siswa kelas VII MTs. NW Pagutan terdapat pada nilai $R$ Square yang ada pada Tabel 5:

\section{Tabel 5. Model Summary}

Model Summary

\begin{tabular}{|l|l|r|r|r|}
\hline Model & $\mathrm{R}$ & R Square & $\begin{array}{c}\text { Adjusted R } \\
\text { Square }\end{array}$ & $\begin{array}{c}\text { Std. Error of } \\
\text { the Estimate }\end{array}$ \\
\hline 1 &, $794^{\mathrm{a}}$ &, 631 &, 609 & 5,853 \\
\hline
\end{tabular}

a. Predictors: (Constant), Kecerdasan Emosional 
Tabel di atas menjelaskan besarnya nilai korelasi/hubungan (R) yaitu sebesar 0,794. Dari output tersebut diperoleh koefisien determinasi ( $\mathrm{R}$ Square) sebesar 0,631 yang mengandung pengertian bahwa pengaruh variabel bebas Kecerdasan Emosional $(\mathrm{X})$ terhadap variabel terikat Hasil Belajar (Y) adalah sebesar 63,1\%, dan sisanya yaitu 36,9\% adalah pengaruh yang belum diteliti oleh peneliti.

Uji F

Sementara itu untuk memastikan apakah Regresi Linear Sederhana tersebut signifikan atau tidak (dalam arti variabel $\mathrm{X}$ terdapat pengaruh terhadap variabel $\mathrm{Y}$ ), hal ini dapat dibuktikan dengan melakukan uji hipotesis dengan cara membandingkan nilai signifikan dengan probabilitas 0,05. Adapun hasil output dari perhitungan SPSS 21 ini dapat di lihat pada Tabel 6:

Tabel 6. ANOVA ${ }^{a}$

ANOVA $^{\text {a }}$

\begin{tabular}{|ll|r|r|r|r|r|}
\hline Model & & \multicolumn{1}{c|}{$\begin{array}{c}\text { Sum of } \\
\text { Squares }\end{array}$} & df & Mean Square & \multicolumn{1}{c|}{$\mathrm{F}$} & Sig. \\
\hline 1 & Regression & 994,282 & 1 & 994,282 & 29,020 &, $000^{\mathrm{b}}$ \\
& Residual & 582,455 & 17 & 34,262 & & \\
& Total & 1576,737 & 18 & & & \\
\hline
\end{tabular}

a. Dependent Variable: Hasil Belajar

b. Predictors: (Constant), Kecerdasan Emosional

Berdasarkan table di atas diperoleh $\mathrm{F}_{\text {hitung }}$ sebesar 29,020 dan $F_{\text {tabel }} \mathrm{n}=19$, df $=\mathrm{n}-\mathrm{k}$ (19-2) sebesar 4,45. Dari data tersebut diketahui bahwa $F_{\text {hitung }}>F_{\text {tabel }}$. Dengan nilai $F_{\text {hitung }}$ sebesar 29,020 sedangkan nilai signifikansi (Sig.) sebesar 0,000 lebih kecil dari probabilitas ( $\mathrm{p}=$ $0,000<0,05)$, maka model regresi dapat dipakai untuk memprediksi variabel hasil belajar atau dengan kata lain ada pengaruh variabel kecerdasan emosional $(\mathrm{X})$ terhadap variabel hasil belajar (Y) matematika siswa kelas VII MTs. NW Pagutan.

Dari hasil penelitian diketahui bahwa kecerdasan emosional ini adalah salah satu faktor yang berasal dari dalam diri seseorang, seperti memotivasi diri terutama dalam proses belajar. Setiap siswa yang memiliki kecerdasan emosional tinggi akan mendapatkan hasil belajar yang optimal. Itu sebabnya kecerdasan emosional ini sangat penting dalam dunia pendidikan. Kecerdasan emosional sangatlah penting dalam dunia pendidikan, dan sangat bermanfaat jika diterapkan. Karena kecerdasan emosional ini adalah salah satu faktor yang bisa mempengaruhi hasil belajar siswa, tingkat kecerdasan emosional siswa berbeda-beda sehingga hasil belajar siswa juga cenderung berbeda. Ada yang memiliki Intelligence Quotient (IQ) tinggi namun Emotional Quotient (EQ) rendah, ada juga yang memiliki Intelligence Quotient (IQ) rendah namun kecerdasan emosional tinggi. Anak yang memiliki Emotional Quotient (EQ) tinggi cenderung lebih aktif dan lebih ulet atau giat dalam mengerjakan tugas serta fokus dalam menerima materi ketika pembelajaran berlangsung. Namun sebaliknya jika kecerdasan emosionalnya rendah cenderung siswa itu akan lebih mudah frustasi dan cepat menyerah jika tidak bisa menjawab soal ketika dalam proses pembelajaran berlangsung. Itu berarti ada faktor lain yang mempengaruhi hasil belajar siswa. 
Dari hasil penelitian diperoleh nilai R Square (koefisien determinasi) sebesar 0,631. Ini berarti bahwa sumbangan efektif yang diberikan kecerdasan emosional terhadap hasil belajar sangat besar, yaitu sebesar $63,1 \%$, sedangkan sisanya yaitu sebesar $36,9 \%$ dipengaruhi oleh faktor-faktor lainnya. Faktor-faktor tersebut dapat berupa faktor internal (yang berasal dari dalam diri individu) atau faktor eksternal (faktor yang berasal dari luar individu). Hal tersebut menunjukkan bahwa kecerdasan emosional berpengaruh terhadap hasil belajar. Hal ini juga sejalan dengan pandangan Goleman, bahwa kecerdasan intelektual (IQ) hanya menyumbang $20 \%$ bagi kesuksesan, sedangkan $80 \%$ adalah sumbangan faktor-faktor keutamaan lain, dalam kecerdasan emosional atau Emotional Quotient (EQ) yakni suatu kemampuan seseorang untuk menguasai emosinya melalui kesadaran diri, pengaturan diri, motivasi diri, empati, dan keterampilan sosial.

\section{Kesimpulan}

Berdasarkan hasil penelitian tentang Pengaruh Kecerdasan Emosional terhadap Hasil Belajar Matematika siswa kelas VII MTs. NW Pagutan dengan pengujian kevalidan teknik probabilitas yang menunjukkan bahwa nilai Sig. kecerdasan emosional siswa sebesar 0,000, dimana nilai signifikansi lebih kecil dari probabilitas $(\alpha=0,05)$, maka dapat diambil kesimpulan bahwa terdapat pengaruh yang signifikan antara kecerdasan emosional terhadap hasil belajar matematika siswa kelas VII MTs. NW Pagutan.

\section{Referensi}

Andrianto, Taufiq, Tuhana. Mengembangkan Karakter Sukses Anak di Era Cyiber. Jogjakarta: Ar-Ruzz Media, 2011

Astuti, Mulya, Alfira. Statistika Penelitian. Mataram: Insan Madani Publishing, 2016.

Emzir. Metodologi Penelitian Pendidikan Kuantitatif dan Kualitatif. Jakarta: Rajawali Pers, 2011.

Febriana, Nurul. Pengarub Kecerdasan Emosional Terbadap Hasil Belajar Pada Mata Pelajaran Ekonomi (Studi Kasus pada Siswa Kelas XI IPS MAN 12 Jakarta). 2017.

Goleman, Daniel. Emotional Intelligence Terjemahan T. Hermaya. Jakarta: PT Gramedia Pustaka, 2007.

Goleman, Daniel. Emotional Intelligence. Terj. T. Hermaya. Jakarta: Gramedia Pustaka Utama, 2015.

https://www.spssindonesia.com/2014/02/uji-linearitas-dengan-program-spss.html?m=1

https://www.spssindonesia.com/2015/05/cara-uji-normalitas-shapiro-wilkdengan.html? $\mathrm{m}=1$

Purnama, Mayang, Indah. Pengaruh Kecerdasan Emosional Dan Minat Belajar Terhadap Prestasi Belajar Di Sman Jakarta Selatan. Jurnal Formatif, (Vol. 6 No.3 92016)).

Purwanto, Ngalim, M. Psikologi Pendidikan. Bandung: PT Remaja Rosdakarya Offset, 2007.

Rusman. Belajar dan Pembelajaran. Jakarta: Kencana, 2017.

Sarwono, W. Sarlito, Pengantar Psikologi Umum. Jakarta: Rajawali Pres, 2013

Subana, Moersetyo Rahadi, dan Sudrajat. Statistik Pendidikan, (Bandung: CV.Pustaka Setia, 2005. 
Sudjana. Dasar-dasar Proses Belajar Mengajar. Bandung: Sinar Baru Algasindo, Sugiyono. Metode Penelitian Administrasi. Cet. V; Bandung : Alfabeta, 2008.

Sugiyono. Metode Penelitian Kuantitatif Kualitatif Dan R\&D. Bandung: Alfabeta, 2011.

Uno, B. Hamzah. Orientasi Baru dalam Psikologi Pembelajaran. Jakarta: PT Bumi Aksara, 2012. 